University of Nebraska - Lincoln DigitalCommons@University of Nebraska - Lincoln

USGS Staff -- Published Research

US Geological Survey

2015

\title{
Dynamic rupture models of earthquakes on the Bartlett Springs Fault, Northern California
}

Julian C. Lozos

Stanford/USGS, Menlo Park, California, USA, jlozos@stanford.edu

Ruth A. Harris

USGS, Menlo Park, California

Jessica R. Murray

USGS, Menlo Park, California

James J. Lienkaemper

USGS, Menlo Park, California

Follow this and additional works at: http:// digitalcommons.unl.edu/usgsstaffpub

Lozos, Julian C.; Harris, Ruth A.; Murray, Jessica R.; and Lienkaemper, James J., "Dynamic rupture models of earthquakes on the Bartlett Springs Fault, Northern California" (2015). USGS Staff -- Published Research. 864.

http://digitalcommons.unl.edu/usgsstaffpub/864

This Article is brought to you for free and open access by the US Geological Survey at DigitalCommons@University of Nebraska - Lincoln. It has been accepted for inclusion in USGS Staff -- Published Research by an authorized administrator of DigitalCommons@University of Nebraska - Lincoln. 


\section{Geophysical Research Letters}

\section{RESEARCH LETTER}

10.1002/2015GL063802

Key Points:

- Rupture on the BSF is confined to locked patches

- The BSF can still produce strong earthquakes

- Geodetic inversions can be used to inform rupture model setup

Supporting Information:

- Figures S1-S4 and Tables S1 and S2

Correspondence to:

J.C. Lozos,

jlozos@stanford.edu

\section{Citation:}

Lozos, J. C., R. A. Harris, J. R. Murray, and J. J. Lienkaemper (2015), Dynamic rupture models of earthquakes on the Bartlett Springs Fault, Northern California, Geophys. Res. Lett., 42, 4343-4349, doi:10.1002/2015GL063802.

Received 10 MAR 2015 Accepted 14 MAY 2015 Accepted article online 18 MAY 2015 Published online 5 JUN 2015
This document is a U.S. government work and is not subject to copyright in the United States.

(C2015. American Geophysical Union. All Rights Reserved.

\section{Dynamic rupture models of earthquakes on the Bartlett Springs Fault, Northern California}

\author{
Julian C. Lozos ${ }^{1}$, Ruth A. Harris ${ }^{2}$, Jessica R. Murray², and James J. Lienkaemper ${ }^{2}$ \\ ${ }^{1}$ Stanford/USGS, Menlo Park, California, USA, ${ }^{2}$ USGS, Menlo Park, California, USA
}

Abstract The Bartlett Springs Fault (BSF), the easternmost branch of the northern San Andreas Fault system, creeps along much of its length. Geodetic data for the BSF are sparse, and surface creep rates are generally poorly constrained. The two existing geodetic slip rate inversions resolve at least one locked patch within the creeping zones. We use the 3-D finite element code FaultMod to conduct dynamic rupture models based on both geodetic inversions, in order to determine the ability of rupture to propagate into the creeping regions, as well as to assess possible magnitudes for BSF ruptures. For both sets of models, we find that the distribution of aseismic creep limits the extent of coseismic rupture, due to the contrast in frictional properties between the locked and creeping regions.

\section{Introduction}

The Bartlett Springs Fault (BSF) is the easternmost branch of the San Andreas Fault system in Northern California (Figure 1). It is a $170 \mathrm{~km}$ long NW trending right-lateral fault with a slip rate of up to $7.8 \mathrm{~mm} / \mathrm{yr}$ [Murray et al., 2014]. With the San Andreas and Maacama Faults, the BSF is one of the primary structures accommodating plate boundary strain north of San Francisco Bay [Lienkaemper, 2010]. It is the northern continuation of the Calaveras-Green Valley-Berryessa system; like those faults, it exhibits aseismic creep along much of its length [McFarland et al., 2009]. The BSF is more remote than the other faults in the system, resulting in relatively sparse geodetic data along its length [Lienkaemper et al., 2014; Murray et al., 2014]. Therefore, the distribution of creep and locking along the BSF is poorly constrained.

While the physics of creep are important in characterizing the behavior of the BSF over the full seismic cycle, this study only focuses on the coseismic period for several reasons. First, only coseismic rupture produces ground shaking, which makes characterizing coseismic behavior critical for hazard assessment. Aseismic creep may accommodate stored strain that is not released during coseismic rupture, but it does not produce ground shaking in and of itself; its impact on infrastructure is gradual and localized. Second, we want to investigate whether stress changes induced during dynamic, coseismic rupture can make parts of the fault that exhibit aseismic creep rupture coseismically. Multicycle simulations of subduction zones [e.g., Liu and Rice, 2005; Segall and Bradley, 2012] show that stress concentrations induced by multiple slow slip events may promote coseismic slip in creeping zones. However, previous dynamic rupture modeling studies of single ruptures on simplified, partially creeping faults suggest that coseismic rupture remains confined to locked regions [e.g., Lozos, 2013], unless the locked and creeping sections are comparably sized [Noda and Lapusta, 2013]. Thus, as details of the creep distribution and its influence on on-fault stresses may affect probable rupture behaviors and lengths, we conduct dynamic models of coseismic rupture on two different interpretations of the geometry, creep distribution, and creep rate of the BSF.

Our first coseismic dynamic rupture model is based on the geodetic inversion results of Murray et al. [2014, hereinafter M2014]. Their geodetically inferred interseismic slip model is based on permanent and campaign GPS data for the BSF, Maacama, and San Andreas Faults and is designed to fit observed station velocities for all three faults. Their interseismic slip rate model accommodates creep rate uncertainties but requires a simplified fixed vertical subfault geometry. Their inversion results in a single locked patch at the surface of the central BSF and a creep rate of $7.8 \pm 1.2 \mathrm{~mm} / \mathrm{yr}$ below $5 \mathrm{~km}$ (Figure 2a). This contrasts the typical interpretation that faults exhibiting surface creep are likely locked at depth [Savage and Lisowski, 1993]. This could also be interpreted as shallow locking on the BSF, as the creep rate below $5 \mathrm{~km}$ in the inversion is identical to the maximum overall BSF slip rate (M2014). 


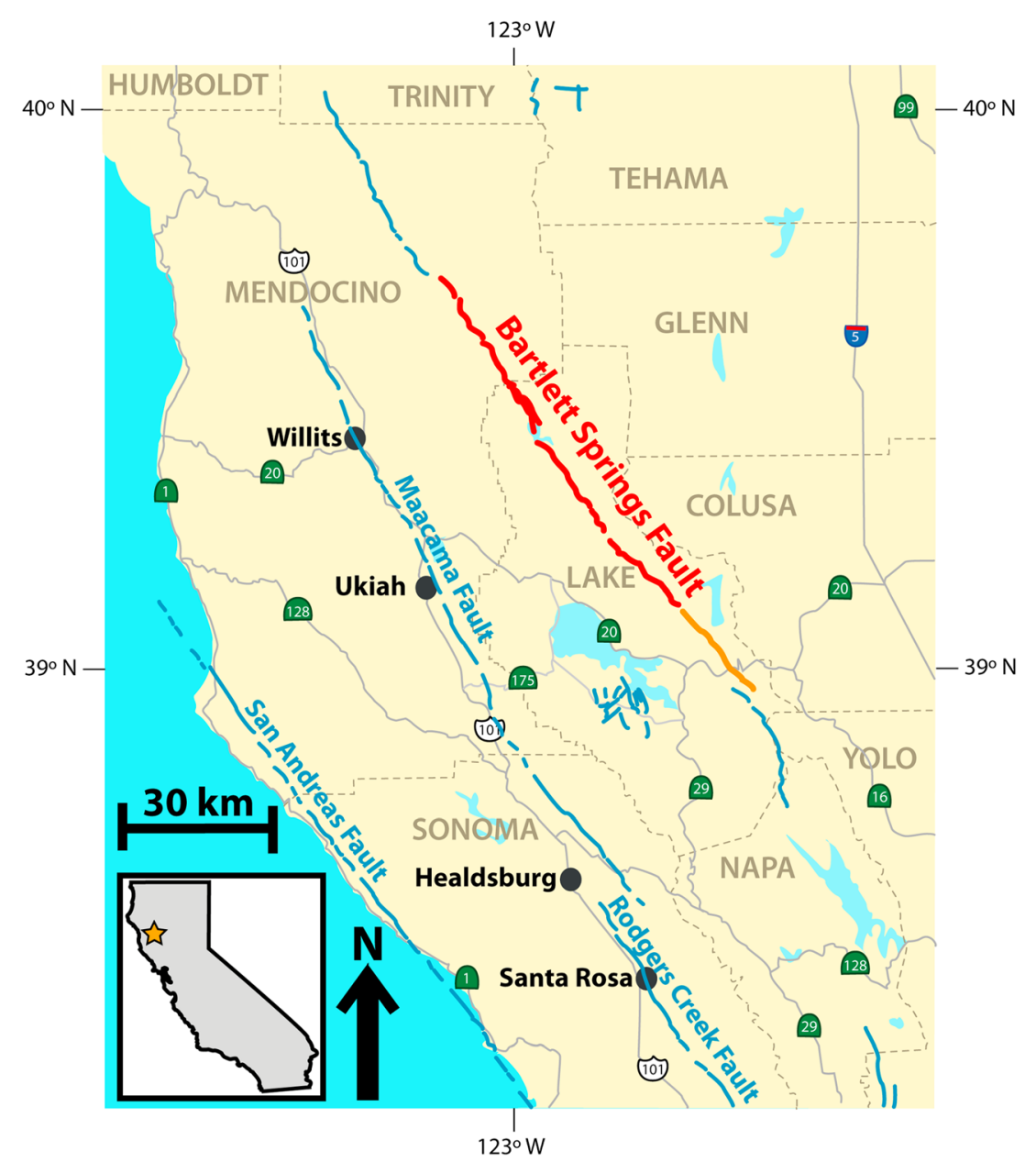

Figure 1. Map of the northern San Andreas Fault system, after Lienkaemper [2010]. The BSF is marked in red and orange. Red sections are included in both the M2014 and L2014 fault parameterizations; orange parts are only in L2014 models. Dashed gray lines are county lines, solid gray lines indicate freeways, and black dots mark cities.

Our second coseismic dynamic rupture model is based on the results of Lienkaemper et al. [2014, hereinafter L2014]. Creep rates in their geodetic model are inferred from alinement arrays and GPS, including some of the same GPS data used in M2014. The L2014 inversion describes a longer section of the fault and uses a more complex vertical fault geometry than in the M2014 inversion. Along-strike segmentation in the L2014 model is based on mapped discontinuities along the fault trace. L2014 incorporates uncertainty in locking depth on each fault segment, as well as creep rate uncertainty (Figure $2 b$ ).

\section{Methods}

We use the 3-D finite element code FaultMod [Barall, 2009], which has been rigorously tested in the Southern California Earthquake Center code comparison exercise [Harris et al., 2009], to model dynamic spontaneous coseismic ruptures based on the M2014 and L2014 BSF interseismic slip rate patterns. Table 1 lists physical and computational parameters implemented in our models. Fault meshes for both the L2014 and M2014 geometries are shown in Figure 2. We embed the faults in a 1-D velocity structure [Castillo and Ellsworth, 1993] (Table S1 in the supporting information).

We test two types of right-lateral strike-slip stress field for our dynamic rupture simulations. In our uniform traction models, all points within a given fault patch have the same initial stresses, regardless of fault orientation; the only along-strike heterogeneity is related to the distribution of creep rates. In 

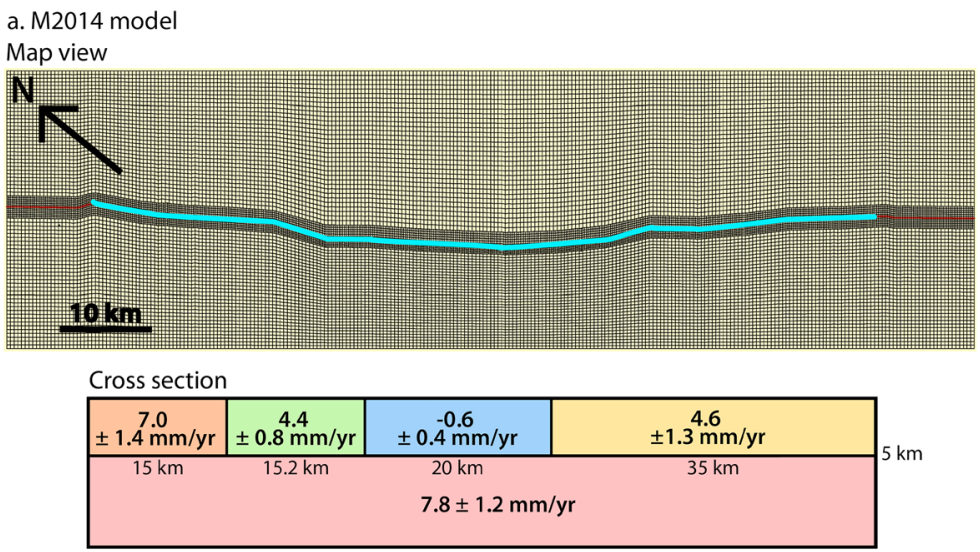

b. L2014 model

Map view
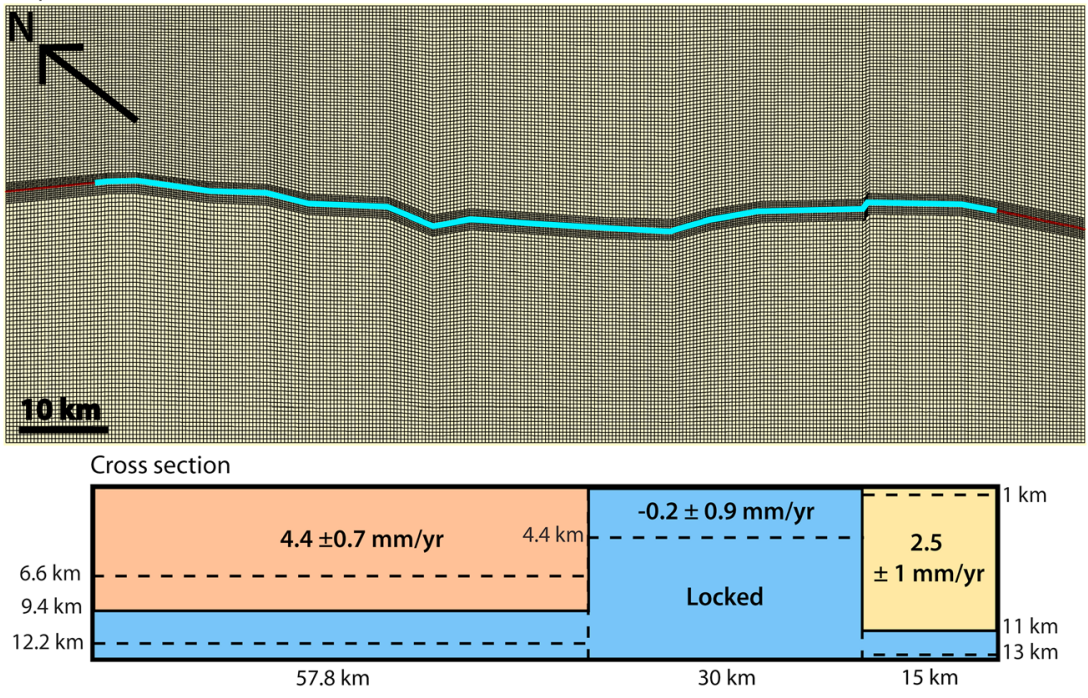

Figure 2. (top) Fault geometry (map view) and (bottom) creep distribution (cross section) for the (a) M2014 and (b) L2014 models of the BSF. In the map view, the blue line represents the model fault length. In the cross sections, solid lines delineate fault patches, and dashed lines show error bars in locking depth. Locked patches are shaded blue.

our regional stress models, a stress tensor with a homogeneous maximum horizontal compression orientation of N26E [Provost and Houston, 2003] is resolved differently on each element of the fault mesh based on its orientation, resulting in heterogeneous initial stresses along strike, even within a given patch.

Table 1. Physical and Computational Parameters Parameters

Values

Principal vertical stress $\sigma_{\mathrm{v}}$ Principal north-south stress $\sigma_{\mathrm{NS}}$

Principal east-west stress $\sigma_{\mathrm{EW}}$ Density

Static coefficient of friction $\mu_{\mathrm{s}}$

Dynamic coefficient of friction $\mu_{\mathrm{d}}$

Slip-weakening critical distance

Regional stress orientation

Element size

Fault length

Fault basal depth

Forced nucleation radius
We assign a stress drop of $9 \mathrm{MPa}$ below $7 \mathrm{~km}$ depth to interseismically locked parts of the fault. We represent decreasing confining stress toward the Earth's surface by tapering stress drop to $0 \mathrm{MPa}$ over the top $7 \mathrm{~km}$ of the fault. These assignments are based on values for earthquakes on the partially creeping Hayward Fault, which have a median stress drop of $9 \mathrm{MPa}$ over all depths and $5 \mathrm{MPa}$ over the top $7 \mathrm{~km}$ [Hardebeck and Aron, 2009].

Our simulations represent single coseismic ruptures and therefore do not 
Table 2. Stresses for Mean Creep Rate Case

\begin{tabular}{lccc} 
Creep Rate & $\mu_{\mathrm{d}}$ & $\mu_{\mathrm{s}}$ & Stress Drop \\
\hline \multicolumn{4}{c}{ M2014 Case Y: Mean Creep Rates } \\
$-0.6 \mathrm{~mm} / \mathrm{yr}$ & 0.2 & 0.6 & $9 \mathrm{MPa}$ \\
$4.4 \mathrm{~mm} / \mathrm{yr}$ & 0.3545 & 0.6 & $2.0545 \mathrm{MPa}$ \\
$4.6 \mathrm{~mm} / \mathrm{yr}$ & 0.36077 & 0.6 & $2.2283 \mathrm{MPa}$ \\
$7.0 \mathrm{~mm} / \mathrm{yr}$ & 0.43487445362 & 0.6 & $0 \mathrm{MPa}$ \\
$7.8 \mathrm{~mm} / \mathrm{yr}$ & 0.459664 & 0.6 & $-6.6611 \mathrm{MPa}$ \\
& & \\
Locked & L2014 Case R: Mean Creep Rates \\
$-0.2 \mathrm{~mm} / \mathrm{yr}$ & 0.2 & 0.6 & $9 \mathrm{MPa}$ \\
$2.5 \mathrm{~mm} / \mathrm{yr}$ & 0.2 & 0.6 & $9 \mathrm{MPa}$ \\
$4.4 \mathrm{~mm} / \mathrm{yr}$ & 0.43487445362 & 0.6 & $0 \mathrm{MPa}$ \\
& 0.600132 & 0.6 & $-0.9992 \mathrm{MPa}$ \\
\hline
\end{tabular}

incorporate the physics of postseismic or interseismic fault slip. Instead, we implement different initial stress conditions for the fault patches inferred to be interseismically locked versus creeping. Using slip-weakening friction [Ida, 1972; Andrews, 1976], we parameterize interseismically locked patches with our chosen maximum positive stress drop and interseismically creeping patches with either negative stress drop [e.g., Ryan and Oglesby, 2014], zero stress drop, or lower positive stress drop than assigned to locked regions. While negative stress drop is not conducive to coseismic rupture, stress changes induced by rupture within regions of positive stress drop may dynamically drive the rupture into regions of negative initial stress drop. Hereafter, we use "locked" and "creeping" to refer to these regions of different stress drops in our coseismic rupture models, as they correlate spatially with regions of interseismic locking and creep in the M2014 and L2014 geodetic models.

We assign the highest stress drop to locked patches and choose stress drop values for other patches proportionally based on the range of interseismic slip rates within each geodetic inversion. We achieve these values by varying the dynamic coefficient of friction while holding initial stresses constant. Both the M2014 and L2014 inversions include negative creep rates on some fault patches; we parameterize these sections as if they had a creep rate of zero. Table 2 lists stress and friction parameters for mean creep rate and depth models for our M2014 and L2014-based simulations; Table S2 in the supporting information lists our parameters based on $\pm 1 \sigma$ creep rates from both inversions.

We nucleate our model earthquakes by raising the shear stress to $10 \%$ above the yield stress and forcing propagation over a distance larger than the critical patch size required for self-sustaining rupture [Day, 1982]. We choose a nucleation point midway along strike at the base of the locked patch.

\section{Results}

Regardless of fault parameterization and stress state, the majority of the slip and moment release in our dynamic rupture simulations occurs within the fully locked fault patches. Creeping regions with positive or neutral stress drops can sustain coseismic slip, though the amount and extent of this slip is controlled both by stress drop within that region and contrast in stress drop between that region and adjacent ones. Higher stress drops allow more slip over a longer distance. Regions of negative stress drop only experience coseismic slip if the adjacent region has a positive stress drop. This slip is the result of the rupture front slowing to a stop, rather than of self-sustaining propagation.

In our M2014-based models, the largest slip occurs in the center of the locked patch, above the nucleation zone. In our uniform traction models, propagation outside of this patch is uniform along strike, since adjacent
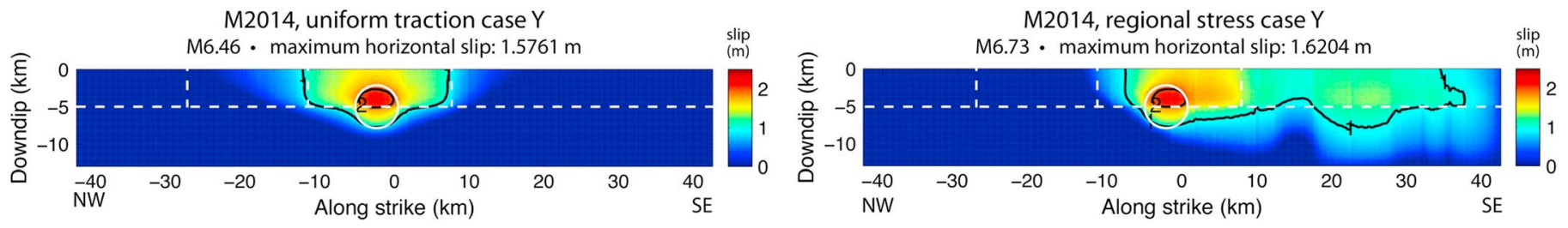

Figure 3. Total slip for dynamic rupture models based on the mean creep rates from the M2014 geodetic inversion, with stresses corresponding to Table 2. Dashed lines mark boundaries between regions of different creep rates, and the white circle marks the forced nucleation zone. In black, $1 \mathrm{~m}$ slip contours are shown. The slip distribution in (left) the uniform traction case is symmetrical within the locked patch, while (right) the regional stress case allows more slip in the creeping zone SE of the locked patch. 


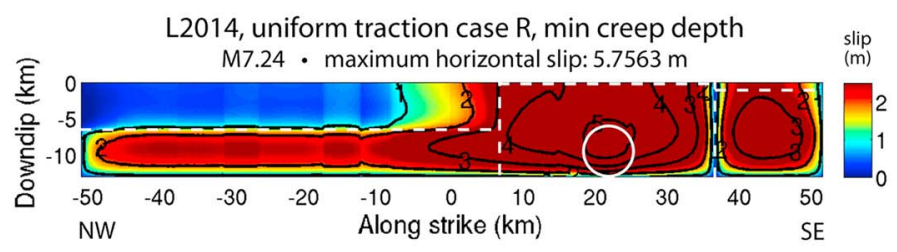

L2014, uniform traction case $R$, mean creep depth

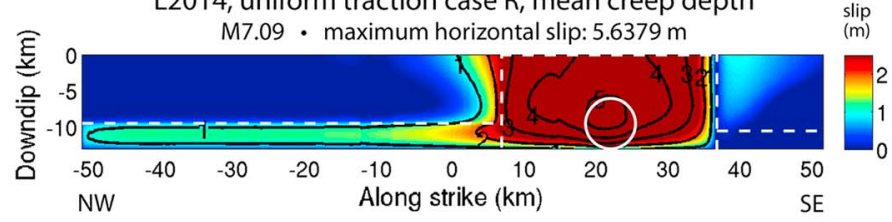

L2014, uniform traction case R, max creep depth

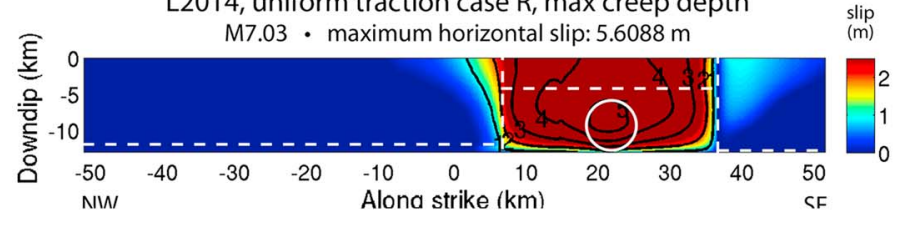

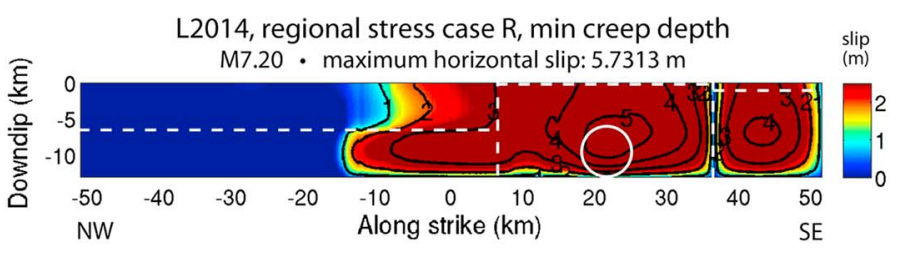

L2014, regional stress case $R$, mean creep depth M7.10 - maximum horizontal slip: $5.6433 \mathrm{~m}$

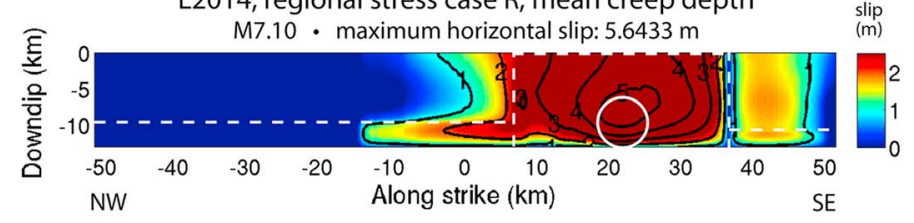

L2014, regional stress case $R$, max creep depth

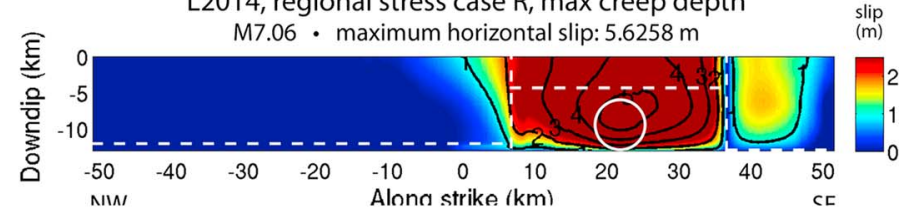

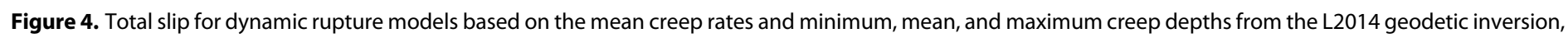
with stresses corresponding to Table 2. As the transition from creep to locking becomes deeper, the amount of slip in the creeping zone decreases.

patches have the same stress drop; in the regional stress model, the fault orientation allows more slip toward the southeast. Initial uniform traction does not allow propagation downdip into the creeping region beyond the forced nucleation zone unless that area is assigned zero stress drop; initial regional stresses allow a small amount of deeper slip to the southeast. Figure 3 shows the slip distribution for a mean creep rate M2014 model, with negative stress drop at the base of the fault and neutral or positive stress drop elsewhere, corresponding to Table 2. Models using stresses based on $\pm 1 \sigma$ of creep rate in the M2014 model are consistent with this pattern; slip plots for those models are in Figures S1 and S2 in the supporting information.

The entire central locked section in our L2014-based models slips coseismically regardless of stress field type or creep depth, whether we use initial stresses based on the mean creep rate or on $\pm 1 \sigma$ from the L2014 mean. As in the M2014 models, the largest slip occurs updip of the nucleation zone. On fault segments adjacent to the central locked patch, assumed creep depth has the strongest effect on rupture behavior and slip distribution. Models with the shallowest transition between creep and locking have the most slip in locked regions and allow more slip into creeping zones. In contrast, models with the deepest creep have very little slip outside of the primary locked section. Figure 4 shows slip distributions for L2014 models with mean creep rates corresponding to Table 2, and minimum, mean, and maximum creep depths, respectively. The difference between uniform traction and regional stress models is less pronounced for L2014 than for M2014 models. Regional stresses impose a barrier to rupture midway through the northwestern section of the fault; this affects rupture extent in the locked part of this section, but has little influence on slip in the creeping part. Slip plots for models with initial stresses based on $\pm 1 \sigma$ in creep rate (Figures S3 and S4) are in the supporting information.

\section{Discussion and Conclusions}

The inability of coseismic rupture to propagate through regions of the BSF that exhibit slip-strengthening behavior is consistent with previous dynamic rupture models of simplified locked patches on planar partially creeping faults [Lozos, 2013]. This is a result of contrast in frictional and stress properties between different fault patches, rather than of how high or low the stresses and frictional coefficients are in an absolute sense; it is also a result of the amount of energy in the rupture front as it negotiates these contrasts. When a rupture front reaches the boundary between a locked patch and a creeping region, more of its energy budget must be directed into fracturing into the creeping zone, rather than propagating forward and radiating seismic energy. If there is no available stress to build up energy ahead of the rupture front, propagation ceases. Cessation is abrupt when the rupture front transitions from a region of positive stress drop to a region of 
negative stress drop, since negative stress drop does not allow energy to build up ahead of the rupture front. Cessation is more gradual for propagation from a region of higher positive stress drop into one of neutral or low positive stress drop, as some energy is generated as the rupture front propagates into the creeping region, but not enough to be self-sustaining.

L2014-based dynamic rupture models produce larger simulated earthquakes than M2014-based dynamic rupture models do, largely because L2014 models include more of the mapped length of the BSF, and a greater percentage of that fault length is fully locked. Additionally, every creeping zone in the L2014 model is adjacent to locked regions on two sides. Rupture in these locked regions wraps around the creeping zones and then propagates inward into them, thus producing more slip. The single locked patch in the M2014 model is surrounded by creep, which keeps outward propagating rupture contained. The fact that the L2014 fault geometry is more complex than the M2014 geometry has no discernible impact on rupture extent in either case. The distribution of creep and locking dominates the rupture behavior in both sets of models. As the additional geometrical complexities in the L2014 models are on a smaller scale than the patches of different stress drops, they only affect small details of the slip distribution. The fault geometry features that are large enough to affect rupture extent are consistent between M2014 and L2014 models.

Compared to uniform traction models, regional stress models produce larger moments for the M2014 parameterization and smaller moments for the L2014 parameterization. In M2014 models, the southeasternmost creeping zone is favorably oriented within the regional stress field. This effectively raises potential stress drop and lowers fault strength on that patch, promoting longer rupture. In contrast, because the locked areas in the L2014 parameterization are larger, they extend across sections of the fault that are both more and less favorable for rupture than in the uniform traction models. Some parts of the locked patch still experience stress drops of $9 \mathrm{MPa}$ or higher, but other parts have lower effective stress drops. The favorable patch toward the southeast end of the fault still promotes more slip in that area, but an unfavorable region toward the northwest end inhibits enough slip that the overall moment of the event is lower than in the equivalent uniform traction model. Using a different regional stress orientation would likely affect the slip distribution and favorability of locked regions to some degree. However, we expect that the contrast in frictional properties will still be the primary controlling factor in where rupture ends.

The M2014 and L2014 parameterizations of the BSF produce large model earthquakes that differ greatly from each other. However, both parameterizations are based on sparse geologic and geodetic data. Because rupture length is controlled by the distribution of locked patches and the amount of available stress drop in creeping regions, more data and, by extension, a more detailed picture of the distribution of creep and locking will allow better assessment of probable BSF rupture behaviors. Additionally, models of the full seismic cycle suggest that long-term creep over multiple earthquake cycles may affect the available stress drop on both locked and creeping sections of a fault [Segall and Bradley, 2012]. A study combining full-cycle models with dynamic rupture models may also allow better understanding of the long-term rupture behavior of the BSF.

Given the current data resolution and creep distribution, it appears that BSF ruptures may be confined to locked regions of the fault: at least to the large well-resolved region near its center. This has several implications. First, surface rupture may be confined to a smaller subsection of the fault. Second, as peak ground motions from ruptures on partially creeping faults are indistinguishable from peak shaking produced by rupture on fully locked faults [Harris and Abrahamson, 2014], ground motions generated by a BSF earthquake may be sizeable. Lastly, sections of the fault that do not slip coseismically may release their slip budget in other ways. Afterslip is well documented after earthquakes on partially creeping faults, such as the M6.0 2004 Parkfield [Johnson et al., 2006] and M9.0 2011 Tohoku-oki events [Johnson et al., 2012]. Afterslip on creeping patches may be vigorous enough to drive postseismic slip on coseismic asperities [Johnson et al., 2012] and may even account for the majority of observed surface offset from rupture on a partially creeping fault [Aagaard et al., 2012]. Thus, there is still risk from slower surface offset along the full BSF, even if a smaller portion ruptures coseismically. As the pattern of strong motion, coseismic displacement, and afterslip are all affected by the distribution of creep on the fault, this emphasizes the need for more data collection for the BSF region.

Our models produce a wide magnitude range: from M6.32 to M7.24. The highest is a L2014 model with the largest locked area and the highest overall stress drop. The lowest is a M2014 model with the highest contrast 


\section{Acknowledgments}

We generate our dynamic rupture models using the 3-D finite element code FaultMod [Barall, 2009]. Our model setup is based on the geodetic inversions of Murray et al. [2014] and Lienkaemper et al. [2014], and we implement a velocity structure [Castillo and Ellsworth, 1993] and stress field orientation [Provost and Houston, 2003] from the literature. All of these studies are accessible in peer-reviewed journals. No other external data were used in this study. The authors would like to thank Norman Abrahamson (PG\&E/UC Berkeley) for support for this study. We would also like to thank Brad Aagaard, Deborah Smith, Michael Floyd, and one anonymous reviewer for their comments and suggestions. The Pacific Earthquake Engineering Research Institute and the USGS-PG\&E CRADA contributed funding to this project. Julian Lozos is supported by a National Science Foundation Earth Science Postdoctoral Fellowship under award EAR-PF-1250143. Any use of trade, firm or product names is for descriptive purposes only and does not imply endorsement by the U.S. Government.

The Editor thanks Michael Floyd and an anonymous reviewer for their assistance in evaluating this paper. in stress drop between the shallow locked patch and the surrounding creeping areas. Considering both end members, as well as potential effects of currently unresolvable smaller-scale heterogeneity on the BSF, the probable magnitude distribution may skew lower than what our models suggest. Further modeling studies incorporating smaller-scale heterogeneity within the locked and creeping zones will be useful for understanding possible rupture behaviors, for the BSF and other partially creeping faults.

\section{References}

Aagaard, B. T., J. J. Lienkaemper, and D. P. Schwartz (2012), Probabilistic estimates of surface and coseismic slip and afterslip for Hayward Fault earthquakes, Bull. Seismol. Soc. Am., 102, 961-979, doi:10.1785/0120110200.

Andrews, D. J. (1976), Rupture propagation with finite stress in antiplane strain, J. Geophys. Res., 81, 3575-3582, doi:10.1029/JB081i020p03575. Barall, M. (2009), A grid-doubling technique for calculating dynamic three-dimensional spontaneous rupture on an earthquake fault, Geophys. J. Int., 178, 845-859, doi:10.1111/j.1365-246X.2009.04190.x.

Castillo, D. A., and W. L. Ellsworth (1993), Seismotectonics of the San Andreas Fault system between Point Arena and Cape Mendocino in Northern California: Implications for the development and evolution of a young transform, J. Geophys. Res., 98, 6543-6560, doi:10.1029/ 92JB02866.

Day, S. M. (1982), Three-dimensional simulation of spontaneous rupture: The effect of nonuniform prestress, Bull. Seismol. Soc. Am., 72, $1881-1902$.

Hardebeck, J. L., and A. Aron (2009), Earthquake stress drops and inferred fault strength on the Hayward Fault, East San Francisco Bay, California, Bull. Seismol. Soc. Am., 99(3), 1801-1814, doi:10.1785/0120080242.

Harris, R. A., and N. A. Abrahamson (2014), Strong ground motions generated by earthquakes on creeping faults, Geophys. Res. Lett., 41, 3870-3875, doi:10.1002/2014GL060228.

Harris, R. A., et al. (2009), The SCEC/USGS dynamic earthquake rupture code validation exercise, Seismol. Res. Lett., 80, 119-126, doi:10.1785/ gssrl.80.1.119.

Ida, Y. (1972), Cohesive force across the top of a longitudinal shear crack and Griffith's specific surface energy, J. Geophys. Res., 77, 3796-3805, doi:10.1029/JB077i020p03796

Johnson, K. M., R. Bürgmann, and K. Larson (2006), Frictional properties on the San Andreas Fault near Parkfield, California, inferred from models of afterslip following the 2004 earthquake, Bull. Seismol. Soc. Am., 96, doi:10.1785/0120050808.

Johnson, K. M., J. Fukuda, and P. Segall (2012), Challenging the rate-state asperity model: Afterslip following the 2011 M9 Tohoku-oki, Japan, earthquake, Geophys. Res. Lett., 39, L20302, doi:10.1029/2012GL052901.

Lienkaemper, J. J. (2010), Recently Active Traces of the Bartlett Springs Fault: A Digital Database, California: U.S. Geol. Surv. Data Ser., vol. 541, U.S. Geol. Surv., Reston, Va.

Lienkaemper, J. J., F. S. McFarland, R. W. Simpson, and S. J. Caskey (2014), Using surface creep rate to infer fraction locked for sections of the San Andreas Fault system in Northern California from alignment array and GPS data, Bull. Seismol. Soc. Am., 104, doi:10.1785/0120140117.

Liu, Y., and J. R. Rice (2005), Aseismic slip transients emerge spontaneously in three-dimensional rate and state modeling of subduction earthquake sequences, J. Geophys. Res., 110, B08307, doi:10.1029/2004JB003424.

Lozos, J. C. (2013), Dynamic rupture and ground motion modeling on realistically complex strike-slip faults, PhD dissertation, Univ. of California, Riverside.

McFarland, F. S., J. J. Lienkaemper, and S. J. Caskey (2009), Theodolite measurements of creep rates on San Francisco Bay region faults, California, 1979-2012, U.S. Geol. Surv. Open File Rep., 2009-1119.

Murray, J. R., S. E. Minson, and J. Svarc (2014), Slip rates and spatially variable creep on the northern San Andreas system inferred through Bayesian inversion of Global Positioning System data, J. Geophys. Res. Solid Earth, 119, 6023-6047, doi:10.1002/2014JB010966.

Noda, H., and N. Lapusta (2013), Stable creeping fault segments can become destructive as a result of dynamic weakening, Nature, 493 , 518-521, doi:10.1038/nature11703.

Provost, A. S., and H. Houston (2003), Stress orientations in Northern and Central California: Evidence for the evolution of frictional strength along the San Andreas plate boundary system, J. Geophys. Res., 108(B3), 2175, doi:10.1029/2001JB001123.

Ryan, K. J., and D. D. Oglesby (2014), Dynamically modeling fault step overs using various friction laws, J. Geophys. Res. Solid Earth, 119, 5814-5829, doi:10.1002/2014JB011151.

Savage, J. C., and M. Lisowski (1993), Inferred depth of creep on the Hayward Fault, Central California, J. Geophys. Res., 98, 787-793, doi:10.1029/92JB01871

Segall, P., and A. M. Bradley (2012), Slow-slip evolve into megathrust earthquakes in 2D numerical simulations, Geophys. Res. Lett., 39, L18308, doi:10.1029/2012GL052811. 